\title{
THE COMPOUND INFLUENCE OF TEXTURE AND MICROSTRUCTURE ON THE MECHANICAL PROPERTIES OF LOW-C STEEL WIRES
}

\author{
P. GANGLI, J. A. SZPUNAR and SUGONDO \\ Department of Mining and Metallurgical Engineering McGill University, \\ Montreal, Canada H3A $2 A 7$
}

(Received July 18, 1990; in final form September 21, 1990)

\begin{abstract}
A series of experiments were made determining textural, microstructural, and mechanical properties in cold drawn, and spheroidization heat treated low-C steel wires (AISI-1018 and 1033 grades). It was found that texture exerted a significant influence on the mechanical properties, while microstructure had a comparable influence.

Mechanical properties are represented by yield strength (YS), ultimate compressive strength (UCS) and by homogeneous strain energy (EHOM), defined by the integral of stress up to uniform elongation. Textural properties are represented by the Taylor-factor, $M$, the $R$-value, and by the maximum of the orientation distribution function (ODFMAX). Micro-structural properties are treated with the help of the aspect ratio parameter $(1 / \sqrt{ } A R)$, where $A R$ is the grain aspect ratio (length to ellipsoidal width), the grain size parameter $(1 \sqrt{ } D)$, and the mean free path between second phase spheroidized cementites $\sqrt{ } N$.

For cold drawn steel wires, homogeneous strain energy (EHOM) is well correlated to $(1 / \sqrt{ } A R)$ and (ODFMAX). Yield strength, on the other hand, appears to be chiefly influenced by the aspect ratio parameter, thus here ODFMAX exerts less influence. The yield strength (YS) of annealed, spheroidization treated low-C wires are equally influenced by the grain size parameter $(1 / \sqrt{ } D)$, the mean distance between spherulites $(\sqrt{ } N)$ and by ODFMAX.

The textures of the cold drawn wires could be well described by the $\langle 110\rangle$ fibre parallel to wire axis, and by the $\langle 111\rangle$ fibre normal to wire axis. The annealed wires, while also featuring these two fibres, displayed a distinct $\{111\}\langle 110\rangle$ single orientation.
\end{abstract}

KEY WORDS Low-carbon steel, texture, microstructure, aspect ratio, Taylor factor

\section{INTRODUCTION}

The compound influence of texture and microstructure has been recognized for a long time. Case studies on zirconium, titanium as well as dispersion hardened aluminium alloys are known [Moulin (1984), Campagnac (1986) and Jensen (1985)]. Steel however, has received in this context a different kind of attention. Obviously, a trivial approach is to claim that differing microstructures, that also contain different equilibrium or metastable phases of steel, such as ferrite, pearlite, bainite, or martensite, should definitely display different properties. In most cases the problem is that these microstructures exert such an overbearing influence on the mechanical properties, so that smaller effects due to texture are almost negligible. 
In this paper, we show that, at least in the specific case of cold drawn and spheroidization heat treated low-C AISI-1018 and 1033 steel wires texture and microstructure exert commensurate influences. This is, indeed explainable since in the cold drawing process microstructure does not change so drastically, while texture becomes sharper. In a similar manner, during the spheroidization heat treatments, we basically deal with a ferrite with dispersed spherulites. In the case of an unsuccessful spheroidization we most likely have a pearlitic structure. Recrystallization texture, on the other hand, may change again, therefore here we have a case where there is more change in the texture than in the microstructure.

In short we have found that for the case of cold drawn and spheroidization heat treated low-carbon steel wires, we have to treat textural microstructural influences as comparable cause effects.

Literature on the textures of drawn wires is quite abundant. Ettisch et al. (1939) discovered that the preferred orientation which was developed in cold drawn iron wires can be described by the $\langle 110\rangle$ direction parallel to the wire axis. Barrett (1939) also pointed out that this texture is dominant in drawn bcc metals by making experiments with single crystal wires. Although single crystal wires of different orientations were swaged and drawn in different treatments all gave the $\langle 110\rangle$ ideal orientation. He also indicated in his work that the $\langle 110\rangle$ initial orientation did not change in the course of drawing and swaging. The influence of initial texture on the final deformation texture was also studied by Cullity (1958). These workers drew ARMCO iron wires to $96 \%$ RA and found a strong $\langle 110\rangle$ fibre texture. In another work, Bhandary et. al. (1962) swaged Armco iron to $96 \%$ reduction in area and found that most of the grains had the $\langle 110\rangle$ orientation. Gubchevskii and co-workers (1975) investigated fibre textures after drawing low carbon steel wires. He observed $\langle 110\rangle$ and $\langle 114\rangle$ textures. Kanetsuki et al. (1985) drew rods of low carbon steels of $12 \mathrm{~mm}$ in diameter and found the cylindrical textures namely $\{112\}[110]$ at the surface and $\{110\}[110]$ and $\{110\}[114]$ textures in the intermediate layers.

Recrystallization textures in bcc wires have been measured, analyzed, and discussed for many years (e.g. [Bhandary (1962), Gubchevski (1975), and Kanetsuki (1985)]. Given the observation, that bcc wires have a tendency to retain the $\langle 110\rangle$ fibre texture even after primary recrystallization, it is not so surprising that the mean features of the cold drawn texture are retained.

Microstructure of these steels is extremely widely analyzed. Basic microstructural features and particles are routinely given and supplied by manufacturers. A more sophisticated treatment of microstructures that would involve dislocation density, segregation properties, grain-size, and grain-shape distribution are remotely linked to theoretical works e.g. [Abbruzzese and Lücke (1986)] or to a specialized industrial process [Abbruzzese (1989)].

Mechanical properties are again commonly tested, and basic strength of data are supplied by the materials. Since formability and machinability of steel can be improved by spheroidizing cementite in a pearlitic steel [Sellars (1982)], we shall concentrate on spheroidization treated steel wires. We shall make an attempt here to link, analyze and correlate mechanical properties of these wires to textural and microstructural characteristics. 


\section{MATERIAL PREPARATION AND TESTING}

Cold drawn, low-C steel wires (grade AISI 1018 and 1033) were prepared. Rods of $5.53 \mathrm{~mm}$ diameter were drawn without heat treatment in 5 passes up to $78 \%$ RA (area reduction). Drawn samples were then heat treated according to various schedules in order to get slightly different microstructures and to vary the type and the strength of the texture. The chemical composition is given in Table 1 . The drawing schedule for cold drawing is shown in Table 2, while a representative selection of typical annealing schedules are given in Table 3 . Our goal was to obtain sufficient variation for texture, as well as for microstructure, while still

Table 1 Chemical composition of low Carbon steel wire materials

\begin{tabular}{lllll}
\hline AISI Grade & C\% wt. & Mn\% wt. & P\% wt. & S\% wt. \\
\hline 1018 & $0.15-0.20$ & $0.60-0.9$ & $<0.04$ & $<0.05$ \\
1033 & $0.27-0.34$ & $0.60-0.9$ & $<0.04$ & $<0.05$ \\
\hline
\end{tabular}

Table 2 Cold drawing schedule and overview of heat treatment of low-Carbon steel wires

\begin{tabular}{lll}
\hline Sample & $\begin{array}{l}\text { Diameter } \\
{[\mathrm{mm}]}\end{array}$ & $\begin{array}{l}\text { \% Area Reduction } \\
(R A)\end{array}$ \\
\hline 31D & 5.53 & 0 \\
32D & 4.60 & 32 \\
33D & 3.89 & 52 \\
34D & 3.44 & 63 \\
35D & 2.99 & 71 \\
36D & 2.64 & 78 \\
\hline
\end{tabular}

Table 3 Heat treatment schedule for cold-drawn and annealed low-C wires

\begin{tabular}{|c|c|c|c|c|}
\hline \multirow[t]{2}{*}{ Sample } & \multicolumn{2}{|c|}{ Austenizing } & \multicolumn{2}{|c|}{ Spheroidizing } \\
\hline & $\begin{array}{l}\text { Time } \\
\text { hours }\end{array}$ & $\begin{array}{l}\text { Temperature } \\
{ }^{\circ} \mathrm{C}\end{array}$ & $\begin{array}{l}\text { Time } \\
\text { hours }\end{array}$ & $\begin{array}{l}\text { Temperature } \\
{ }^{\circ} \mathrm{C}\end{array}$ \\
\hline 35A4 & 2 & 850 & 3 & 690 \\
\hline $35 \mathrm{~A} 6$ & 2 & 850 & 5 & 690 \\
\hline $35 \mathrm{~A} 7$ & 2 & 850 & 10 & 690 \\
\hline $35 \mathrm{~A} 2$ & 2 & 850 & 15 & 690 \\
\hline $35 \mathrm{~A} 8$ & & & 3 & 690 \\
\hline 35A5 & & & 5 & 690 \\
\hline 35A9 & & & 10 & 690 \\
\hline 35A10 & & & 15 & 690 \\
\hline 35A11 & & & 20 & 710 \\
\hline 35A12 & & & 5 & 710 \\
\hline $35 \mathrm{~A} 13$ & & & 10 & 710 \\
\hline 35A14 & & & 15 & 710 \\
\hline 35A15 & & & 20 & 710 \\
\hline
\end{tabular}


trying to keep our parameters within bounds, so that all specimens still should be comparable. No doubt a drastic quenching would have yielded more significant differences in the microstructure, while a completely different plastic deformation, e.g. bending, or flatten-rolling would have given again totally different textures. Such experiments, however, would have been outside of the practical scope. A totally different, unsuitable geometry for example, serves no practical purpose.

Compression tests were made using 2.5 D (diameter) long specimens, at the strain rate of $E=0.1 / \mathrm{sec}(250 \mathrm{~mm} / \mathrm{sec})$ with an INSTRON machine applying $70 \mathrm{KN}$ max load.

Yield strength (YS), ultimate compressive strength (UCS), and homogeneous strain energy (EHOM), defined as the integral under the stress-strain curve taken up to uniform strain, are determined from respective stress-strain data. Stressstrain curves for cold-drawn AISI-1033 steel are shown in Figure 1. We show curves starting from $0 \%$ RA (reduction in area) to $78 \%$ RA. Stress-strain data for wires after annealing at $710^{\circ} \mathrm{C}$ for 10 hours are shown in Figure 2 (prior cold drawing was $71 \% \mathrm{RA}$ ).

Grains in the cold drawn wires samples are characterized by the aspect ratio parameter $(1 / \sqrt{ } A R)$, where $A R$ is the ratio of the average length of the grains to the average width. After cold drawing grains become elongated, consequently $1 / \sqrt{ } A R$ decreases.

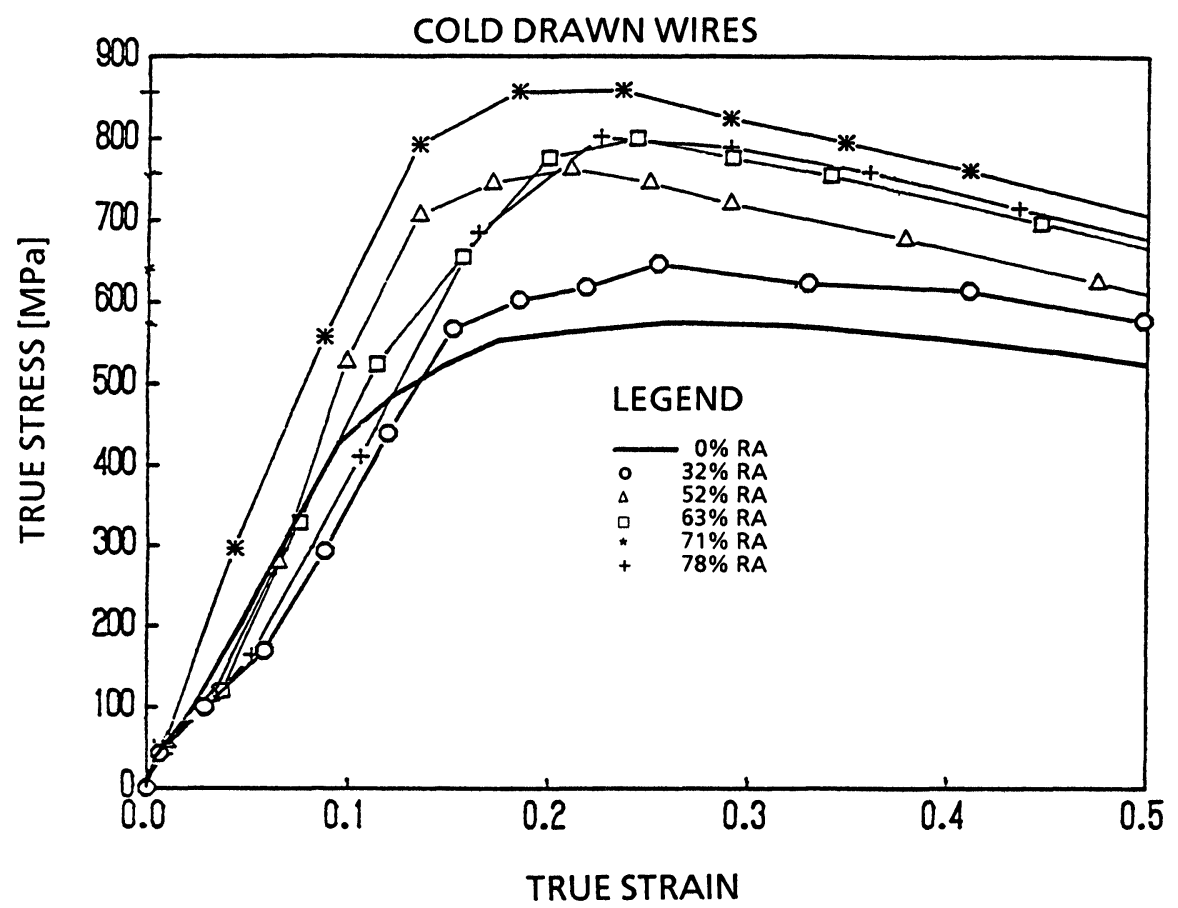

Figure 1 Stress-strain data for the cold drawn wires. Wires were initially cold drawn to (-)0\% RA; (O) $32 \% \mathrm{RA}$; $(\triangle)$ 52\% RA; (口) 63\% RA; (*) 71\% RA; (+) 78\% RA. 


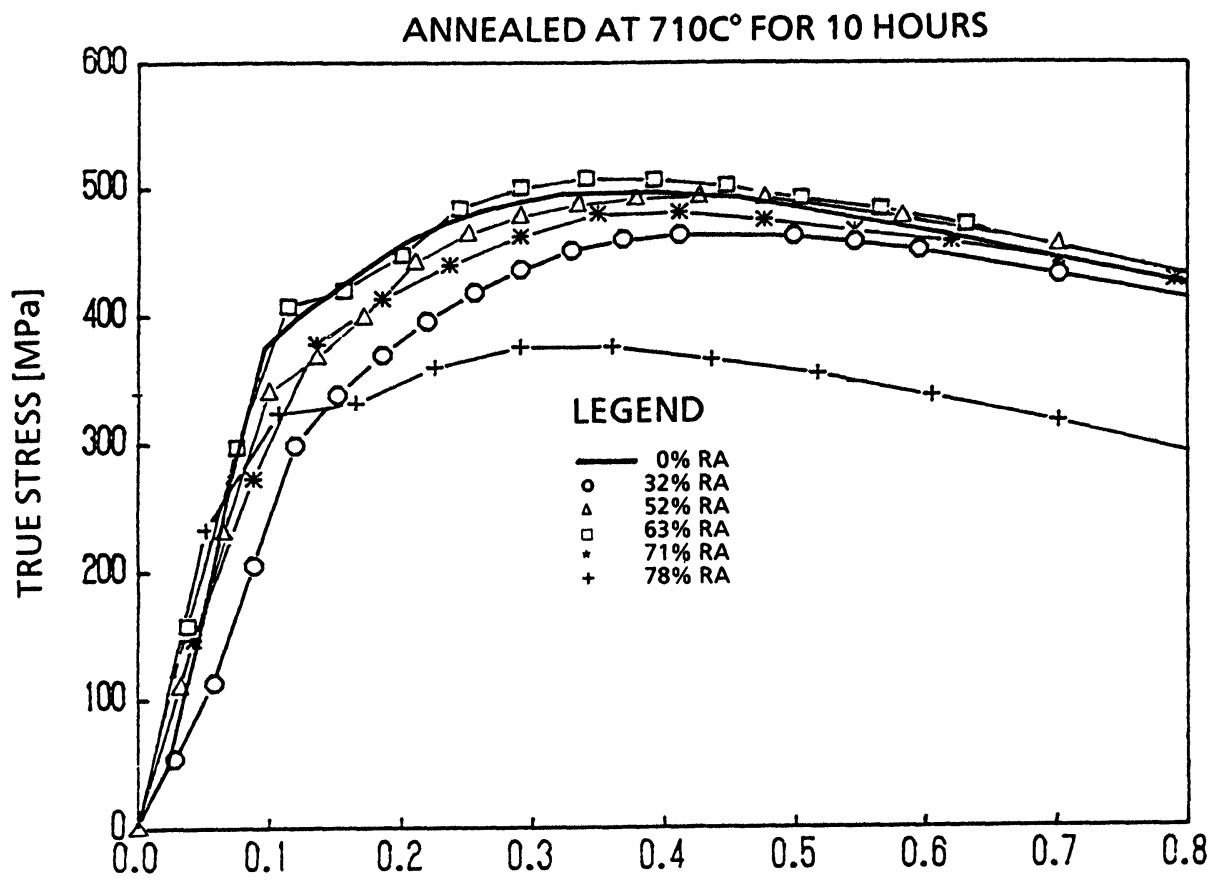

TRUE STRAIN

Figure 2 Stress-strain data for the series annealed at $710^{\circ} \mathrm{C}$ for 10 hours previously cold drawn to (-)

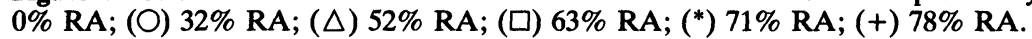

Grain size (D) for the annealed specimens were determined from micrographs by means of Rosiwall's intersection method. The grain size for all annealed specimens ranged from $5.5 \mu \mathrm{m}$ to $15 \mu \mathrm{m}$. The mean distance data for the spherulites was determined for the cold drawn wires. It is known that secondary particles strongly influence strength and ductility properties [Dieter (1976), Sellars (1982)]. The mean distance between spherulite particles was obtained by counting spherulites in a specific area $(N)$ and taking $(\sqrt{ } N)$ to characterize the distance between particles.

\section{TEXTURE MEASUREMENTS AND ANALYSIS}

The material was cut lengthwise; $25 \mathrm{~mm}$ long wires cut along the wire axis were placed next to each other to form a $25 \times 15 \mathrm{~mm}$ composite, flat specimen. The surface was mechanically ground and polished down to $1 \mu \mathrm{m}$ grit using $\mathrm{Al}_{2} \mathrm{O}_{3}$ powder, and finally etched with $5 \%$ nital for 15 seconds.

Texture measurement were made using a SIEMENS D500 type texture goniometer with Mo tube, using the TEX11/ODF11 SIEMENS software installed on a PDP 11/75 computer. First experimental (110), (200), (211) pole figures were measured in the $\alpha=0^{\circ}-80^{\circ}$ range. The Orientation Distribution Function (ODF) was determined using Bunge's series expansion method [Rollett (1987)]. 


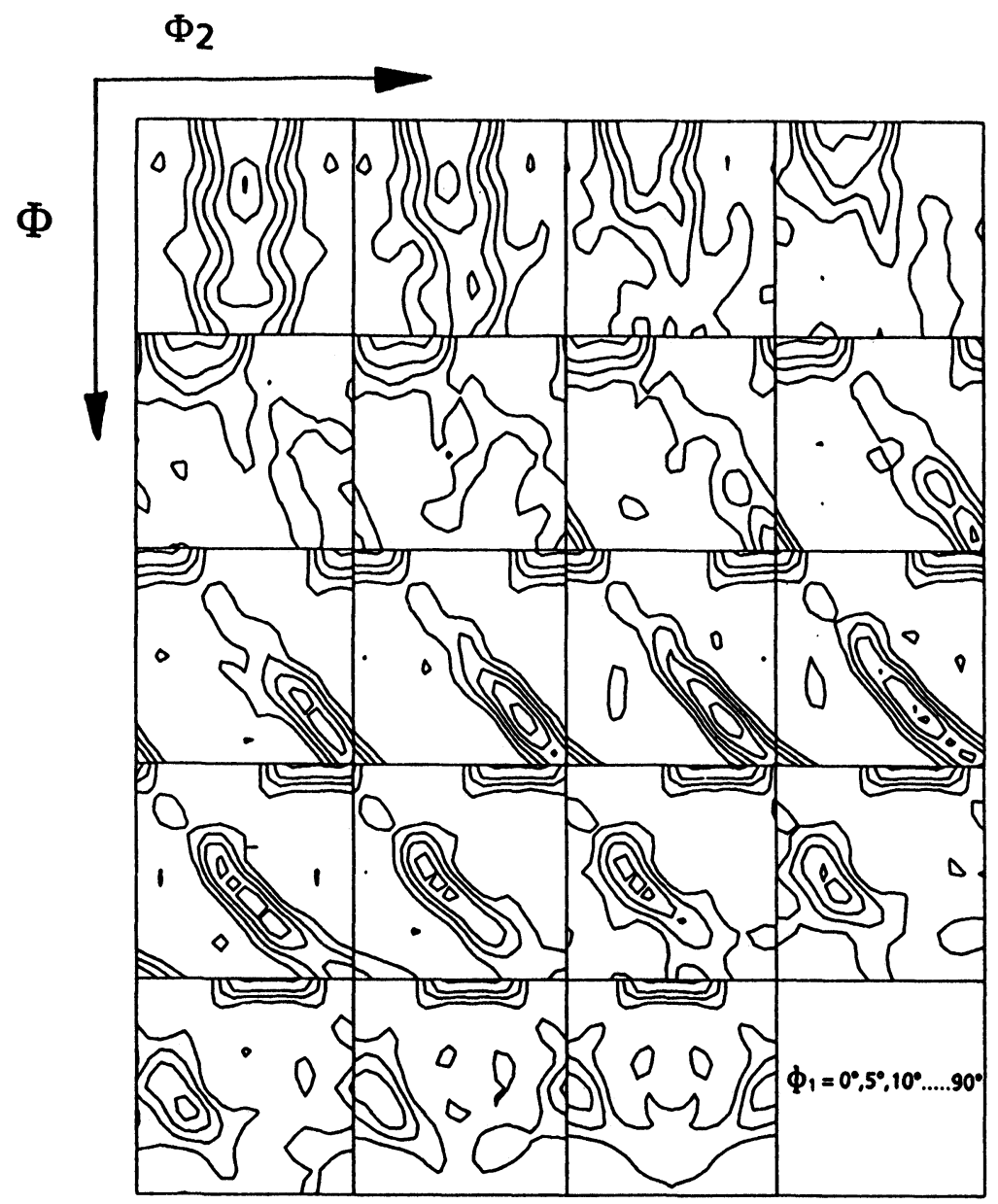

Figure 3a ODF of $71 \%$ cold drawn low-C wire, $\phi_{1}$ sections are shown. Levels 1-2-3-4-5-6 ODFMAX $=6.11$.

Data are represented in the form of (i) ODFs shown in $\phi_{1}$ constant sections, (ii). ODF fibres giving ODF values at particular locations in the orientation space as shown for metal sheets [Schlippenbach (1986), Misra (1984)].

Texture of cold drawn and annealed wires are shown in the form of ODFs presented in $\phi_{1}=0_{1}^{0}, 5^{\circ}, 10^{\circ}, \ldots, 90^{\circ}$ intervals for a typical cold drawn, low-C wire (Sample 35D, after 70\% cold drawing). The main features are the $\langle 110\rangle$ fibre at $\phi_{1}=0^{\circ}, \phi=0^{\circ}-90^{\circ}$, and $\phi_{2}=45^{\circ}$, seen in the $\phi_{1}=0^{\circ}$ section (first upper left block in Figure 3a). This is the fibre that is referred to in the literature as $\alpha$-fibre [Schlippenbach (1986)]. Another noteworthy feature is the $\langle 111\rangle$ fibre, that is $\langle 111\rangle$ normal to the wire axis. This fibre is characterized by $\phi_{1}=0-90^{\circ}$, $\phi=54.5^{\circ}$, and $\phi_{2}=45^{\circ}$ (best seen in the $\phi_{1}=40^{\circ}, 45^{\circ}, 50^{\circ}, \ldots, 90^{\circ}$ sections in Figure 3a). The equivalent of this fibre in bcc metal sheets is referred to as the $\gamma$-fibre [Schlippenbach (1986), Misra (1984)]. Throughout our work we shall use these fibre names. 


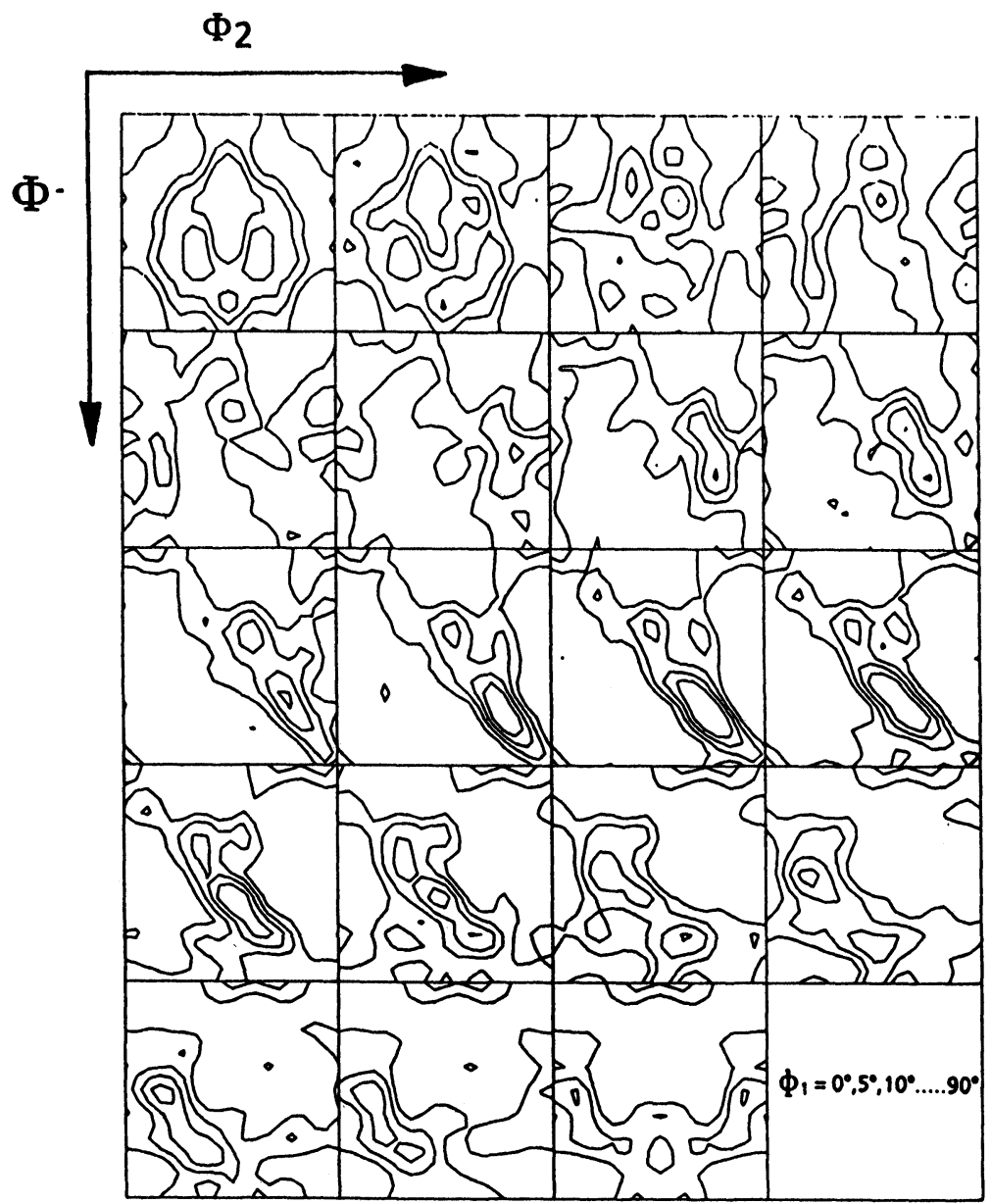

Figure 3b ODF of annealed low-C wire. Prior cold drawing to $71 \%$ RA was followed by a $710^{\circ} \mathrm{C} 20$ hours anneal. $\phi_{1}$ sections are shown. Levels $=1.0-1.5-2.0-2.5$ ODFMAX $=2.9$.

We pointed out that the $\alpha$-fibre, and $\gamma$-fibre as we used them here, had so far been only used for cold rolled bcc metal sheets only [Schlippenbach (1986)]. Given the fact that the same description is also suitable for cold drawn wires, indicates a stronger similarity between cold rolled-, and cold drawn textures in steel. This is rather surprising and indicates that the drawing conditions never exactly correspond to the axialy symmetrical stress and strain states.

Figure $3 \mathrm{~b}$ shows in the texture of a typical, spheroidization heat treated low-C steel wire. Specifically, here we see the ODF of sample 35D, 71\% cold drawn, followed by annealing at $710^{\circ} \mathrm{C}$ for 20 hours. We note that the main change is that the ODF maximum is much lower, ODFMAX dropped down from 6.1 to 2.9. Most of the $\langle 110\rangle$ fibre has become very diffuse. If we look at the $\phi_{1}=0^{\circ}$ section (upper first left block) of Figure $3 b$ we note that we can hardly talk of an $\langle 110\rangle$ 


\section{COLD DRAWN SAMPLES}

\section{a-FIBRES}

$\begin{array}{llll}(001) & (112) & (111) & (110) \\ {[110]} & {[110]} & {[1 T 0]} & {\left[1 \frac{110}{110}\right.}\end{array}$

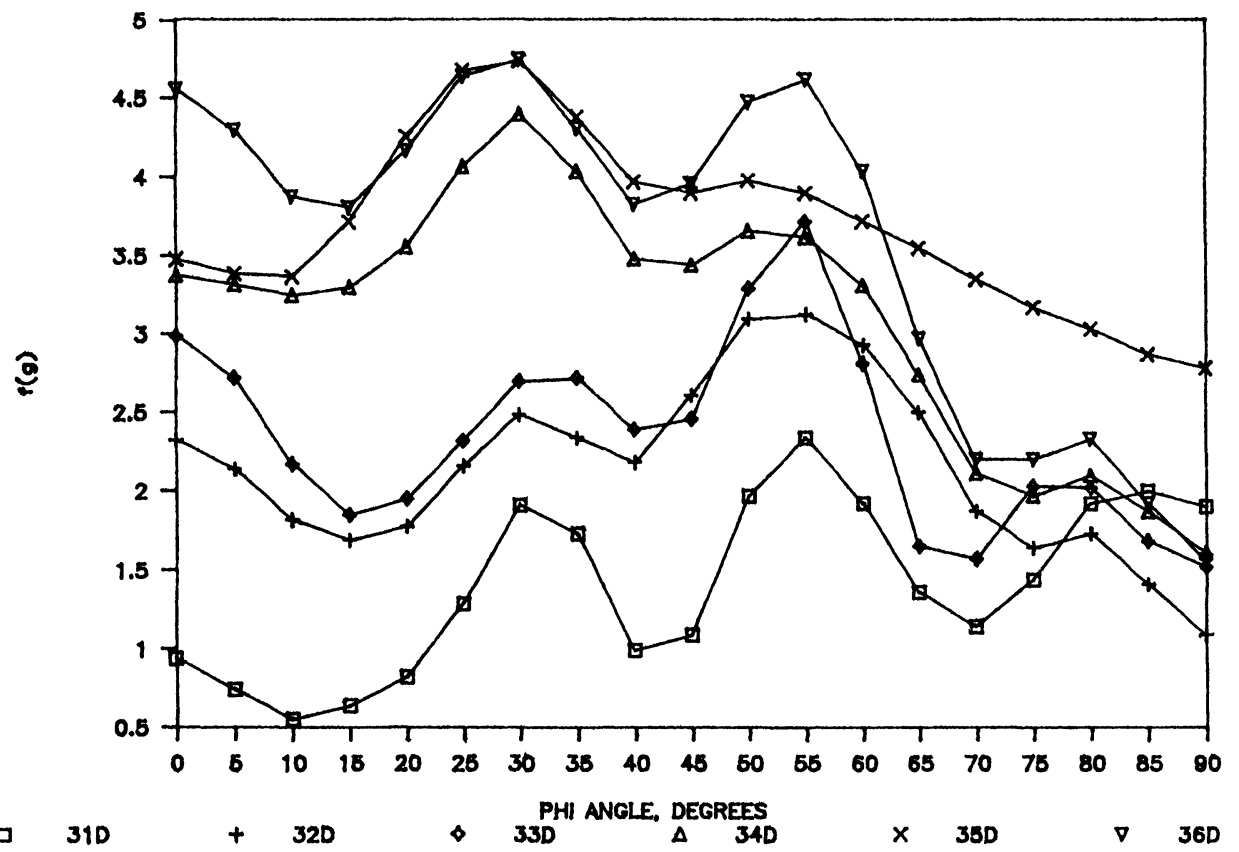

Figure 4a $\alpha$-fibres for cold drawn low-C steel wires, $\left(\langle 110\rangle \|\right.$ wire axis $\phi_{1}=0^{\circ}, \phi=0^{\circ}-90^{\circ}$ and $\left.\phi_{2}=45^{\circ}\right)$; (-) 0\% RA; (+) 32\% RA; $(\diamond)$ 52\% RA; $(\triangle)$ 63\% RA; $(\times) 71 \%$ RA; ( $\left.\nabla\right) 78 \%$ RA.

fibre any more. In the $\langle 111\rangle$ fibre several new components are formed, along $\phi_{1}$, however, $\{111\}\langle 110\rangle$, a cold drawing component, is still the strongest.

An extensive analysis of the $\alpha$, and $\gamma$-fibres for the cold drawn wires is given in Figures $4 \mathrm{a}$ and $4 \mathrm{~b}$. Cold drawn wires are shown in the $0 \%-78 \% \mathrm{RA}$ range. Looking at the $\alpha$-fibres in Figure 4a we note that by increasing the cold drawing reduction we observe a clear tendency: $f(g)$ values in the fibre increase from $f(g)=1$ to $f(g)=4$. This is in good agreement with the general observation that the $\langle 110\rangle$ fibre becomes stronger after cold-drawing (we can speak of a better alignment of the $\langle 110\rangle$ crystal direction parallel to the wire axis). A strong asymmetry in fibre, however, is noted $-f(g)$ values along the $\alpha$-fibre show quite some variation. The corresponding $\gamma$-fibre $(\langle 111\rangle$ normal to WA) is shown in Figure $4 \mathrm{~b}$. Here one high intensity orientation, namely the $\{111\}\langle 110\rangle$ should be singled out. Due to symmetry reasons, this type of orientation appears at $\left(0^{\circ}, 54.5^{\circ}, 45^{\circ}\right)$ and also at $\left(60^{\circ}, 54.5^{\circ}, 45^{\circ}\right)$. The emergence of one single orientation in this fibre is a bit unusual. A more even distribution of the orientations along the $\gamma$-fibre was 


\section{COLD DRAWN SAMPLES}

\section{$Y$-FIBRES}
(111)
(111)
(111)
[1 $1 \overline{1} 0]$
[1 $1 \overline{2} 1]$
[0T1]

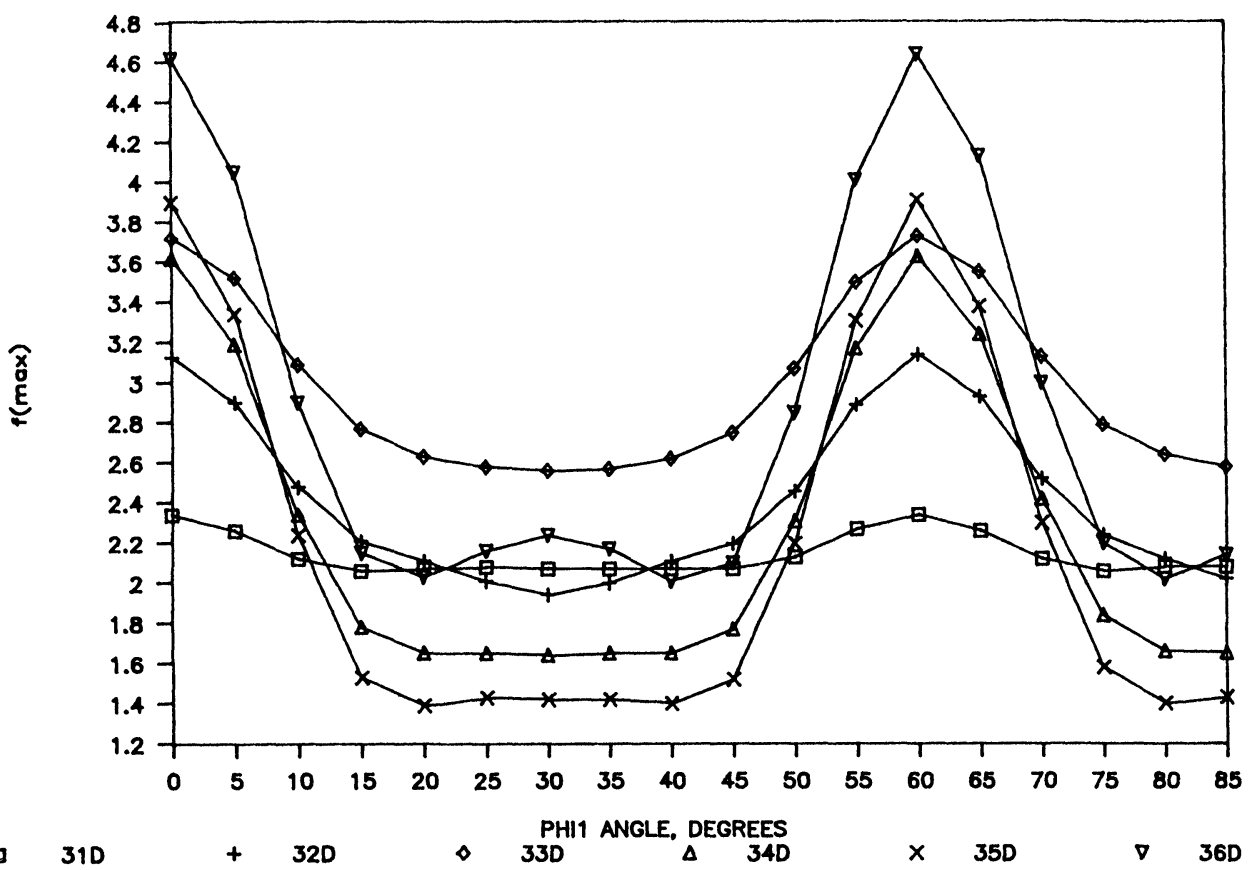

Figure 4b $\gamma$-fibres for cold drawn low-C steel wires, $\left(\langle 111\rangle\right.$ normal to wires axis $\phi_{1}=0-90^{\circ}$, $\left.\phi=54.5^{\circ}, \phi_{2}=45^{\circ}\right) ;(-) 0 \% \mathrm{RA} ;(+) 32 \% \mathrm{RA} ;(\diamond) 52 \% \mathrm{RA} ;(\triangle) 63 \% \mathrm{RA} ;(\times) 71 \% \mathrm{RA} ;(\nabla)$ $78 \%$ RA.

expected. In fact we find that the $\gamma$-fibre (Figure 4b) displays a higher level of asymmetry than that observed typically in cold rolled steels [Schlippenbach (1986)]. The best explanation is offered by considering the composite specimens used for texture measurements. These specimens were machined out parallel to the wire axis, including the total cross section of wire specimens. Hence, these specimens, represent a volume weighted average of the deformation conditions. This implies, that we have a weighted average of the results of the deformation paths taken at the surface and at various through thickness elevations. The net outcome of this texture averaging yielded asymmetrical $\alpha$-fibres, and a $\gamma$-fibre essentially made up of one single component $(\{111\}\langle 110\rangle)$.

Figures $5 \mathrm{a}$ and $5 \mathrm{~b}$ show the respective $\alpha$, and $\gamma$-fibres in annealed specimens after $690^{\circ} \mathrm{C}, 3-5-10-15-20$ hours heat treatment. These wires were previously cold drawn to $71 \%$ RA. These fibres display a general drop in $f(g)$ intensity from 


\section{ANNEALED SAMPLES $690 \mathrm{C}^{\circ}$ a-FIBRES}
$(001)$
(112)
(111)
(110)
[110]
[1 $\mathrm{T} 0]$
[1I0]
[1TO]

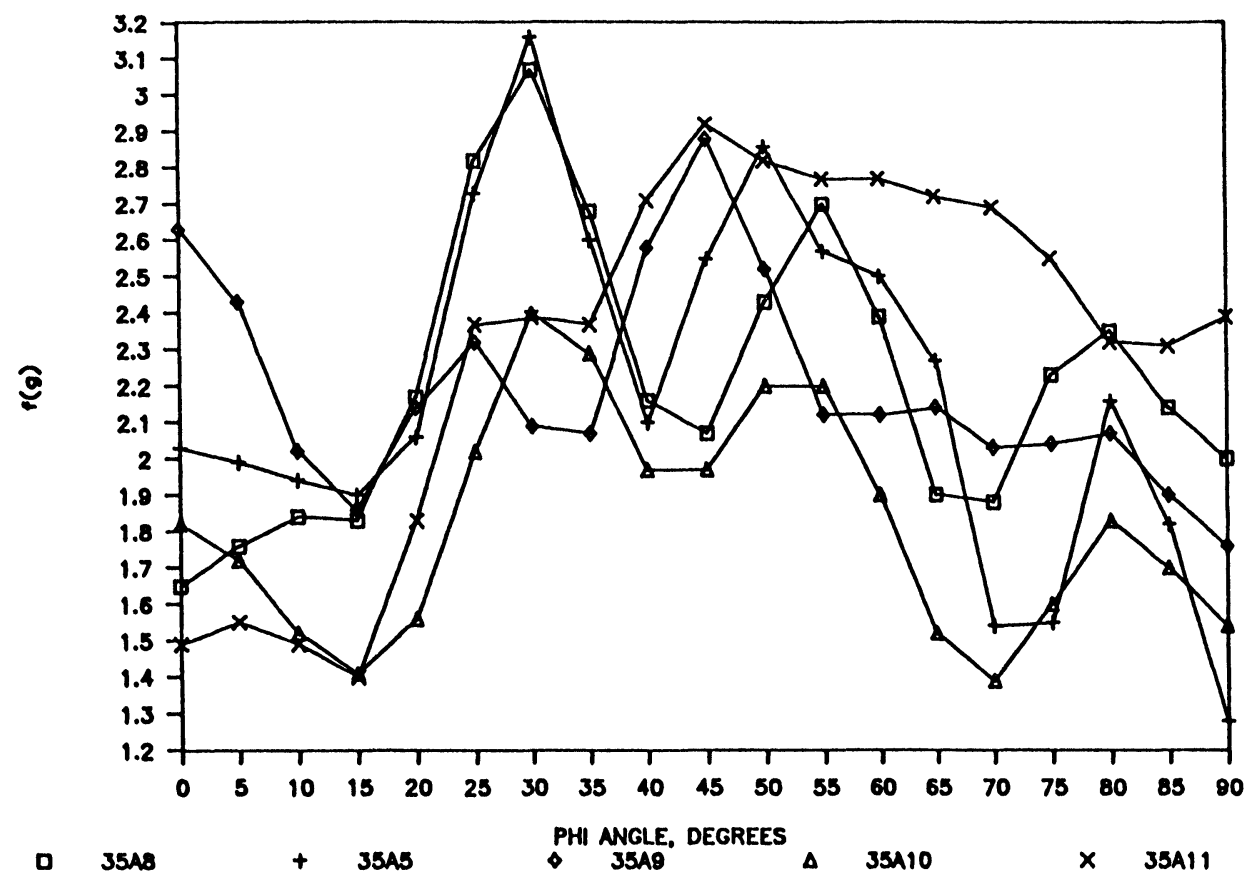

Figure 5a $\alpha$-fibres of specimens $\left(\langle 110\rangle \|\right.$ wire axis $\left.\phi_{1}=0^{\circ}, \phi=0-90^{\circ}, \phi_{2}=45^{\circ}\right)$; annealed to $690^{\circ} \mathrm{C}$. for ( $\square$ 35A8) 3 hours; (+35 A5) 5 hours $(\triangle 35$ A9) 10 hours; $(\triangle 35$ A10) 15 hours; $(\times 35$ A11) 20 hours.

$f(g)=3$ down to $f(g)=1-2$ after 20 hours. The component $\{111\}\langle 110\rangle$ remains strong, while the intensity of other components decreases (cf. sample 35A9 in Figure 5b). Strange as it is, we should point out, that this texture is best approximated by a single component, namely by $\{111\}\langle 110\rangle$.

A similar picture emerges from analyzing the textures of annealed wires after $710^{\circ} \mathrm{C}$ annealed for 5-10-5-20 hours (Figures $6 \mathrm{a}$ and $6 \mathrm{~b}$ ). The holding time of the heat treatment reinforces the formation of the single component $\{111\}\langle 110\rangle$. This tendency at $710^{\circ} \mathrm{C}$, shown in Figures $6 \mathrm{a}$ and $6 \mathrm{~b}$ is much clearer than what we observed at a lower temperature at $690^{\circ} \mathrm{C}$ (Figures 5a and 5b).

In addition to the brief overview of texture development given here, a detailed analysis is given in another work [Sugondo (1990)]. 


\section{ANNEALED SAMPLES $690 \mathrm{C}^{\circ}$ $Y$-FIBRES}
(111)
[110]

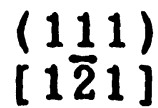
(111)
[0T1]

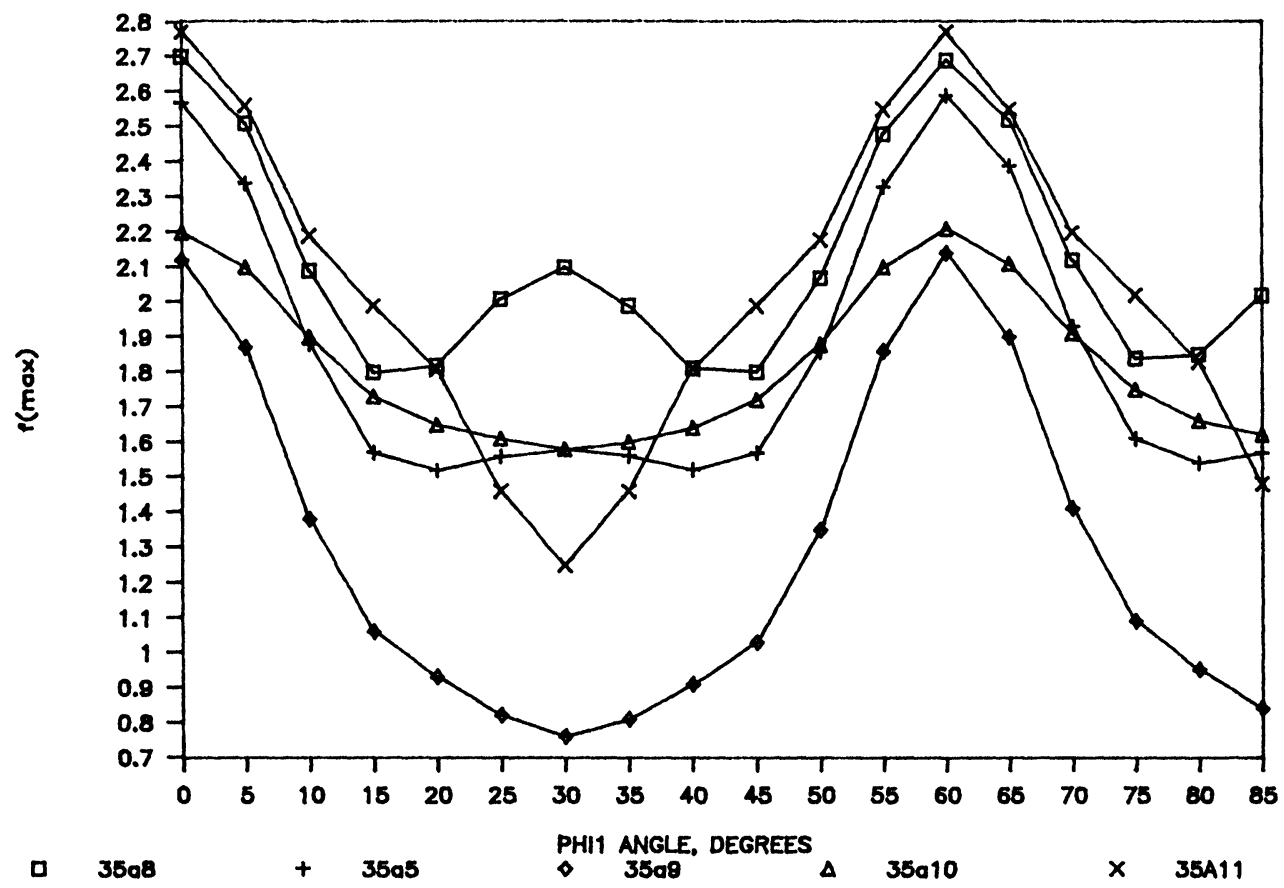

Figure 5b $\gamma$-fibres of specimens $\left(\langle 111\rangle\right.$ normal to wire axis; $\left.\phi_{1}=0-90^{\circ}, \phi=54.5^{\circ}, \phi_{2}=45^{\circ}\right)$ annealed at $690^{\circ} \mathrm{C}$ for $(\square 35 \mathrm{~A} 8) 3$ hours; ( $\left.+35 \mathrm{~A} 5\right) 5$ hours $(\triangle 35 \mathrm{~A} 9) 10$ hours; ( $\left.\triangle 35 \mathrm{~A} 10\right) 15$ hours; ( $\times 35$ A11) 20 hours.

\section{THE CORRELATION OF TEXTURE AND MICROSTRUCTURE TO MECHANICAL PROPERTIES}

In order to establish a correlation of mechanical properties to texture and microstructure we have to define what particular parameters we should determine, analyze and correlate.

Mechanical properties are characterized in this study by yield strength (YS), ultimate compression (UCS) and by the homogeneous strain energy (EHOM) as defined above.

As for choosing texture parameters, we had several alternatives. Taylor factor $M(0), M(90)$, and $R$-values $R(0)$ and $R(90)$ (taken at directions parallel and normal to the wire-axis respectively), and also the value of the maximum ODF (ODFMAX) have all been determined and considered. Taylor-factors and $R$-values were calculated assuming the operation of the $\{110\}\langle 111\rangle$ slip systems, 


\section{ANNEALED SAMPLES $710 \mathrm{C}^{\circ}$ a-FIBRES}

$\begin{array}{llll}(001) & (112) & (111) & (110) \\ {[110]} & {[110]} & {[110]} & {[110]}\end{array}$

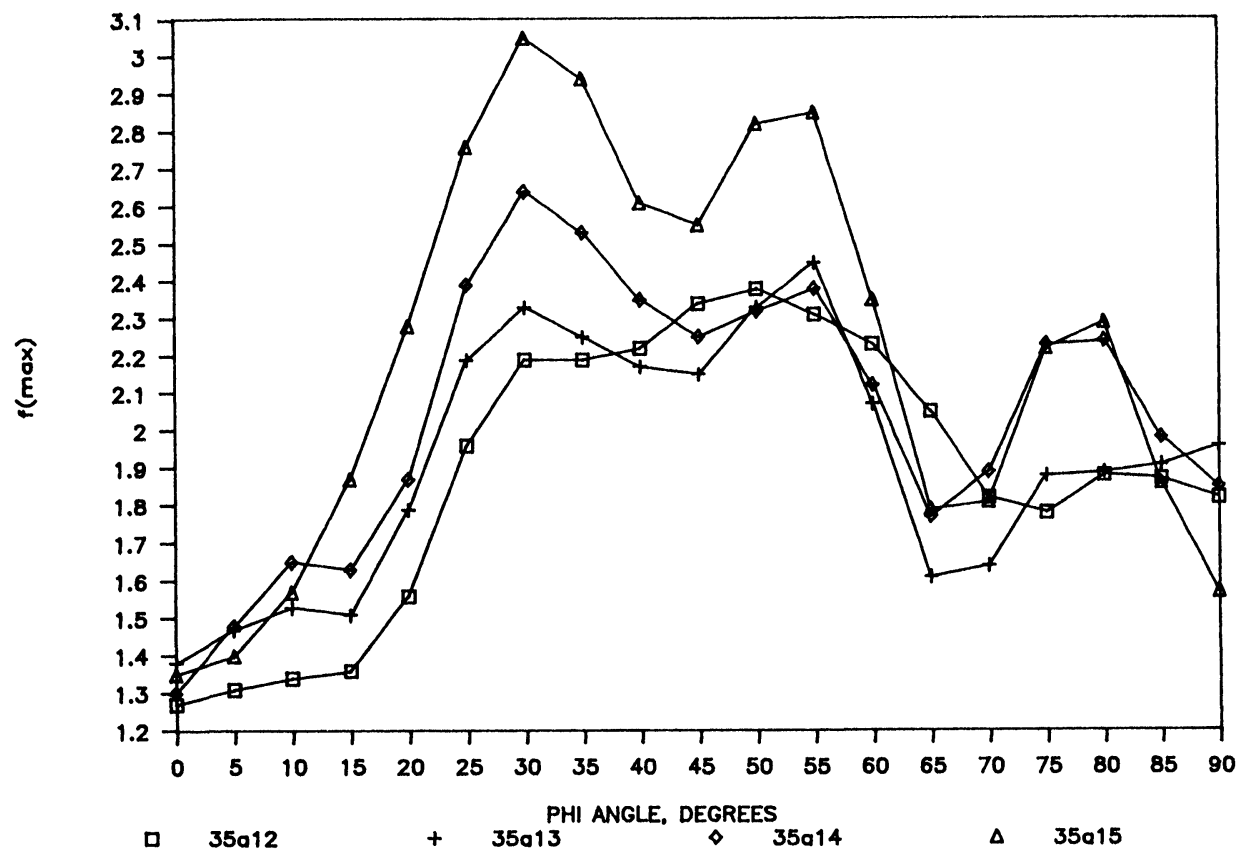

Figure 6a $\alpha$-fibres $\left(\langle 110\rangle \|\right.$ wire axis; $\left.\phi_{1}=0-90^{\circ}, \phi=54.5^{\circ}, \phi_{2}=45^{\circ}\right)$; of specimens annealed at $710^{\circ} \mathrm{C}$ for (35 A12) 5 hours; (+35 A13) 10 hours (35 A14) 15 hours; (35 A15) 20 hours.

while allowing for the partial fulfilment of the strain constraints, using the relaxed constraints principle [Mecking (1979)].

Microstructure could, in fact, be characterized by a large number microscopic and macroscopic parameters. We, for the sake of keeping regression analysis simpler, chose the aspect ratio $(A R)$, the grain sine $D$, and the number of spherulites in a given cross section $(N)$ as the basic parameters. Considering Hall-Petch type relations [Dieter (1976)], we chose $1 / \sqrt{ } A R$, and grain size. Similarly $\sqrt{ } N$ was chosen to characterize the average distance between the spherulites.

Table 4 gives respective textural, microstructural parameter values for the cold drawn series. The same table also includes mechanical property data. A similar data sheet for the annealed wires is presented in Table 5 .

We made a multiple linear regression analysis, making appropriate combinations of these parameters. Figures 7 and 8 show the results of regression analysis for cold drawn steel wires. Figure 7 shows the correlation of homogeneous strain 


\section{ANNEALED SAMPLES $710 \mathrm{C}^{\circ}$ $\checkmark$-FIBRES}
(111)
(111)
(111)
[110]
$[1 \overline{2} 1]$
[0T1]

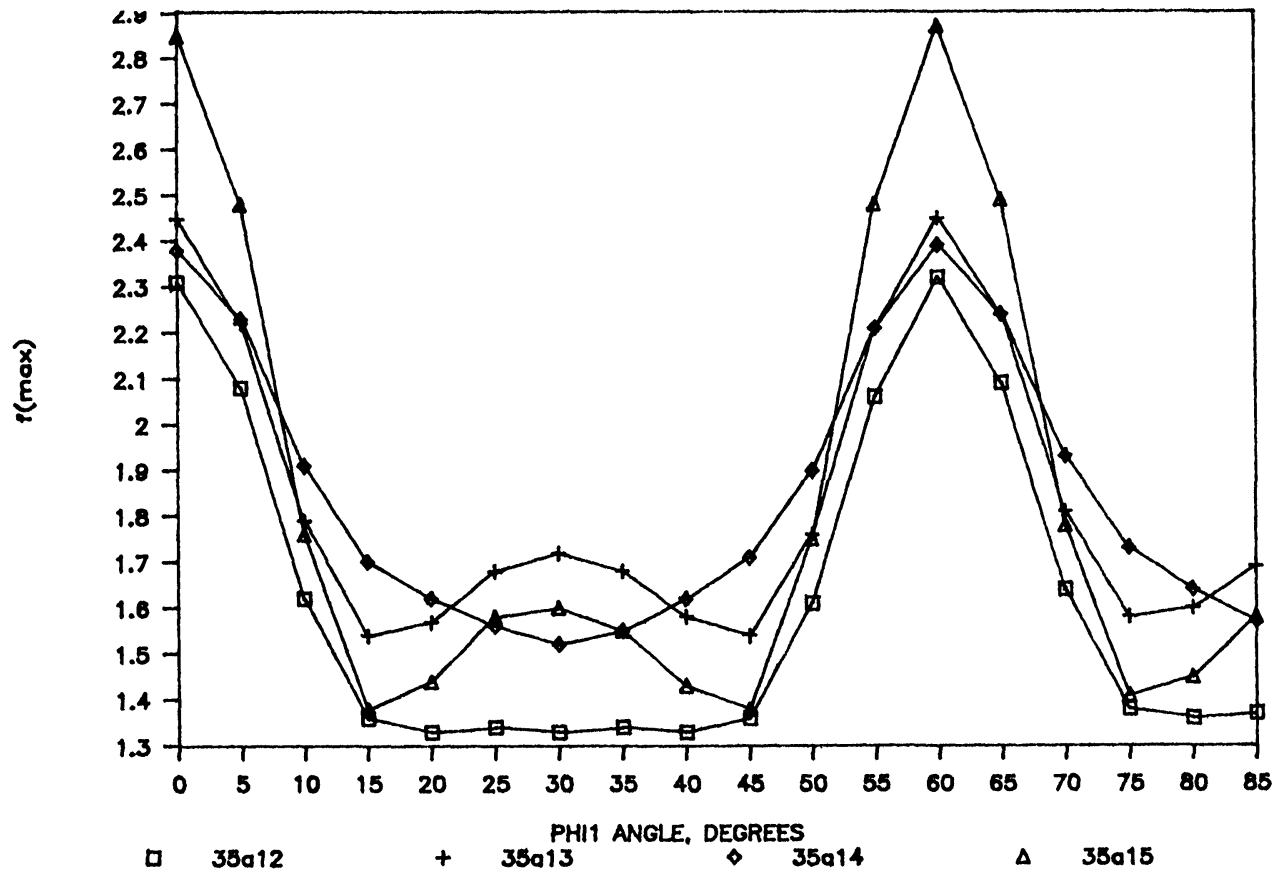

Figure b $\gamma$-fibres of specimens $\left(\langle 111\rangle \|\right.$ wire axis $\left.\phi_{1}=0-90^{\circ}, \phi=54.5^{\circ}, \phi_{2}=45^{\circ}\right)$ annealed at $710^{\circ} \mathrm{C}$ for ( $\square 35$ A12) 5 hours; (+35 A13) 10 hours ( $\diamond 35$ A14) 15 hours; $(\triangle 35$ A15) 20 hours.

(EHOM) as related to the aspect ratio parameter $(1 / \sqrt{ } A R)$ and the texture parameter ODFMAX. The function EHOM is shown in terms of isolines. We note in Figure 7 that both parameters exert an influence of comparable extent.

Table 4 Textural and microstructural data of cold drawn low-C steel wires

\begin{tabular}{lllllll}
\hline Sample & $M(0)$ & $M(90)$ & $R(0)$ & $r(90)$ & ODFMAX & $1 / \sqrt{ } A R$ \\
\hline 0\% RA & 3.084 & 3.092 & 1.45 & 1.45 & 2.4 & 0.975 \\
32\% RA & 3.079 & 3.099 & 1.04 & 1.22 & 3.5 & 0.750 \\
52\% RA & 3.076 & 3.101 & 0.92 & 1.14 & 4.1 & 0.590 \\
63\% RA & 3.076 & 3.119 & 0.96 & 1.22 & 5.6 & 0.505 \\
71\% RA & 3.077 & 3.152 & 1.19 & 1.22 & 6.2 & 0.415 \\
78\% RA & 3.078 & 3.140 & 0.95 & 1.11 & 6.2 & 0.342 \\
\hline
\end{tabular}


Table 5 Texture and microstructural data of spheroidization treated steel wires prior cold drawing $=71 \% \mathrm{RA}$

\begin{tabular}{|c|c|c|c|c|c|}
\hline Sample & $M(0)$ & $M(90)$ & $R(90)$ & ODFMAX & $1 / \sqrt{ } A R$ \\
\hline \multicolumn{6}{|c|}{$\left(850^{\circ} \mathrm{C} 2 \mathrm{~h} ; 690^{\circ} \mathrm{C} 3-5-10-15 \mathrm{~h}\right)$} \\
\hline 35A4 & 3.12 & 3.09 & 1.35 & 3.23 & 0.31 \\
\hline $35 \mathrm{~A} 6$ & 3.13 & 3.10 & 1.51 & 3.47 & 0.29 \\
\hline 35A7 & 3.13 & 3.09 & 1.36 & 3.25 & 0.28 \\
\hline $35 \mathrm{~A} 2$ & 3.14 & 3.09 & 1.19 & 3.31 & 0.33 \\
\hline \multicolumn{6}{|c|}{$\left(690^{\circ} \mathrm{C} 3-5-10-15 \mathrm{~h}\right)$} \\
\hline 35A8 & 3.07 & 3.59 & 1.70 & 3.60 & 0.38 \\
\hline 35A5 & 3.05 & 3.09 & 1.57 & 3.80 & 0.35 \\
\hline 35A9 & 3.01 & 3.03 & 1.37 & 3.70 & 0.35 \\
\hline $35 \mathrm{~A} 10$ & 3.06 & 3.07 & 1.60 & 2.70 & 0.35 \\
\hline \multicolumn{6}{|c|}{$\left(710^{\circ} \mathrm{C} 5-10-15-20 \mathrm{~h}\right)$} \\
\hline 35A12 & 3.07 & 3.06 & 1.62 & 2.50 & 0.35 \\
\hline $35 \mathrm{~A} 13$ & 3.06 & 3.06 & 1.49 & 2.70 & 0.35 \\
\hline 35A14 & 3.05 & 3.05 & 1.63 & 3.70 & 0.35 \\
\hline 35A15 & 3.06 & 3.06 & 1.81 & 3.70 & 0.35 \\
\hline
\end{tabular}

Similar correlations were made, using Taylor factors, $R$-values and even several arbitrary combinations of those together with aspect ratio $(1 / \sqrt{ } A R)$. We generally found that ODFMAX gave a better correlation to mechanical properties than the other texture related parameters.

A similar type of relationship correlating yield strength (YS) to $1 / \sqrt{ } A R$ and

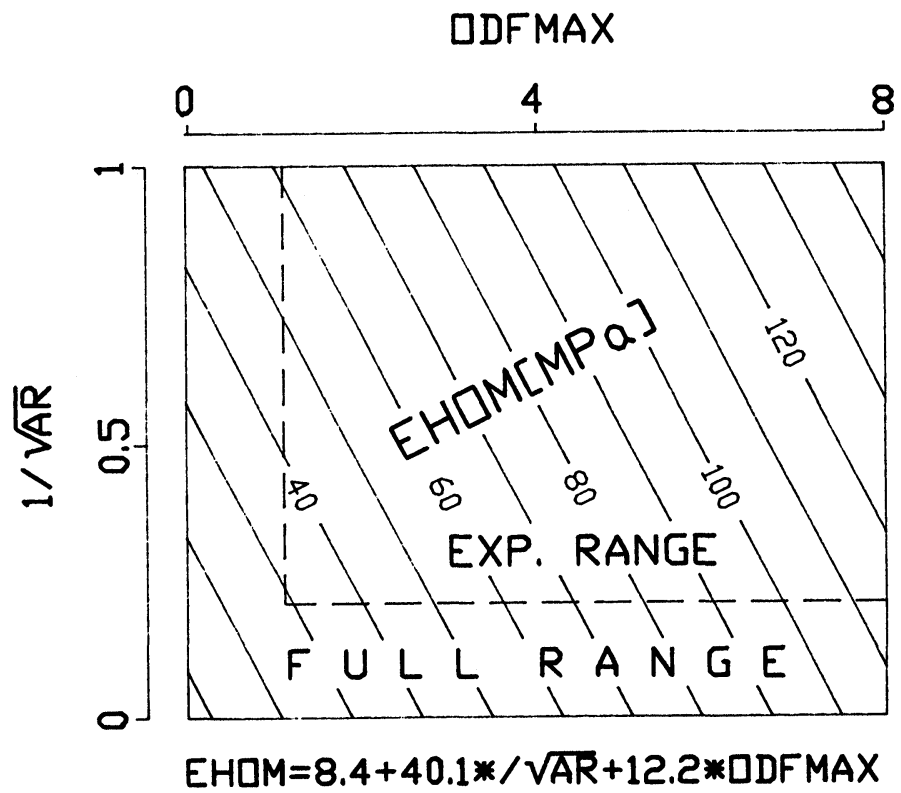

Figure 7 Results of regression analysis of cold drawn wires. The homogeneous strain energy (EHOM) is shown as correlated to the aspect ratio parameter $(1 / \sqrt{ } A R)$, and the texture parameter (ODFMAX). Isolines of EHOM [Mpa] are drawn. 


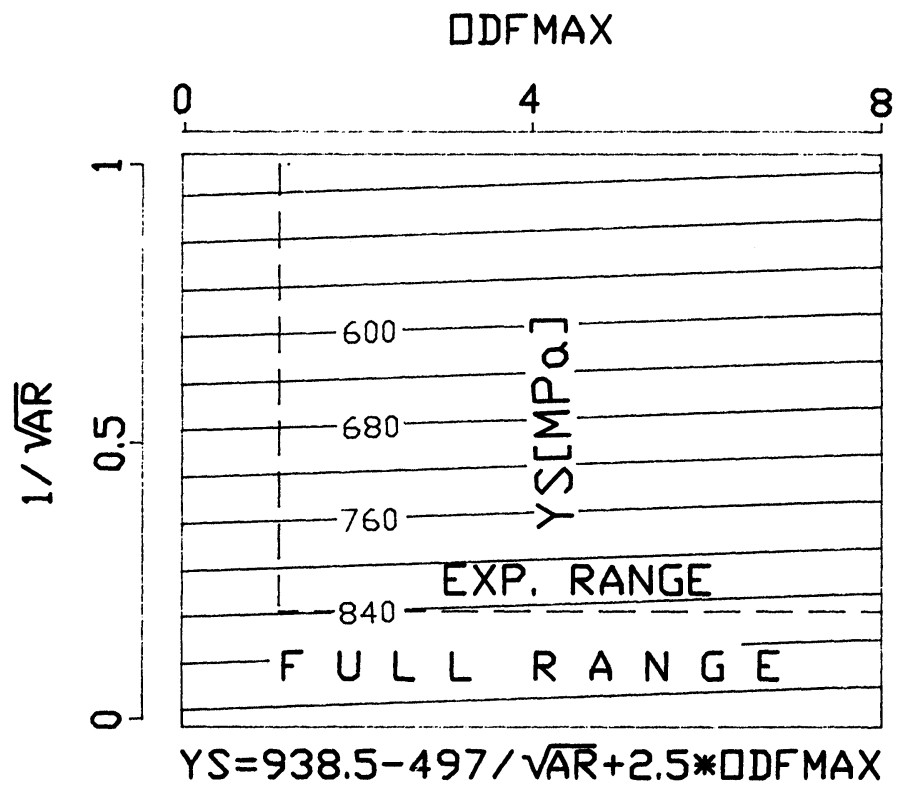

Figure 8 Results of regression analysis of cold drawn wires. Yield strength (YS) is shown as correlated to the aspect ratio parameter $(1 / \sqrt{ } A R)$, and the texture parameter (ODFMAX). Isolines of YS [Mpa] are drawn.

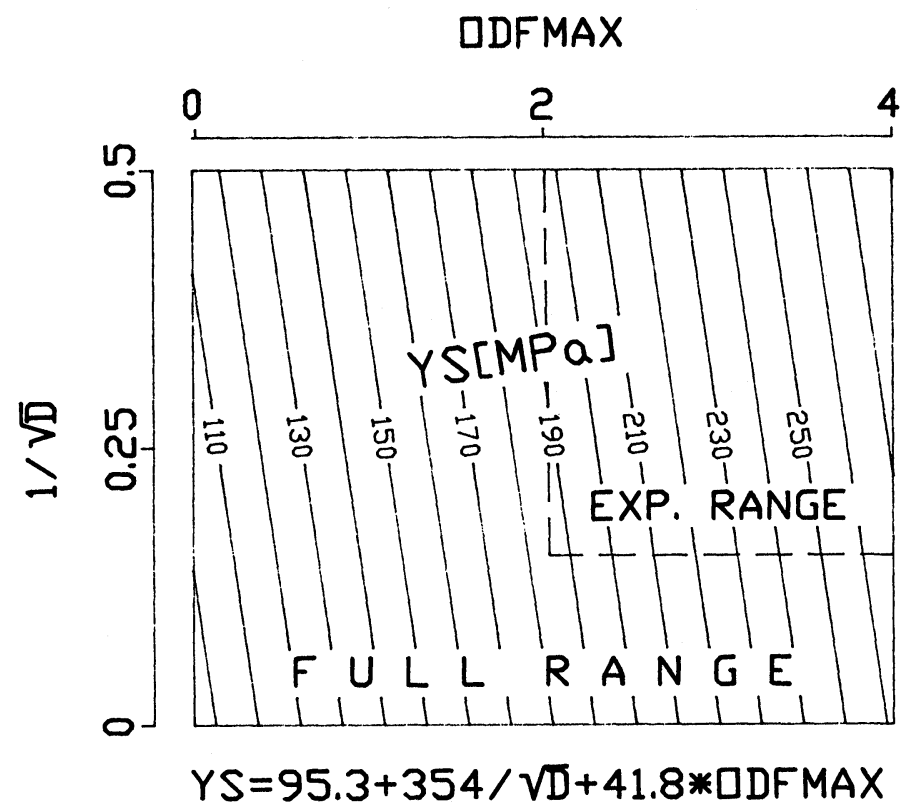

Figure 9 Results of regression analysis of annealed wires. Yield strength (YS) is shown as correlated to the grain size parameter $(1 \sqrt{ } D)$, and the texture parameter (ODFMAX). Isolines of YS [Mpa] are drawn. 


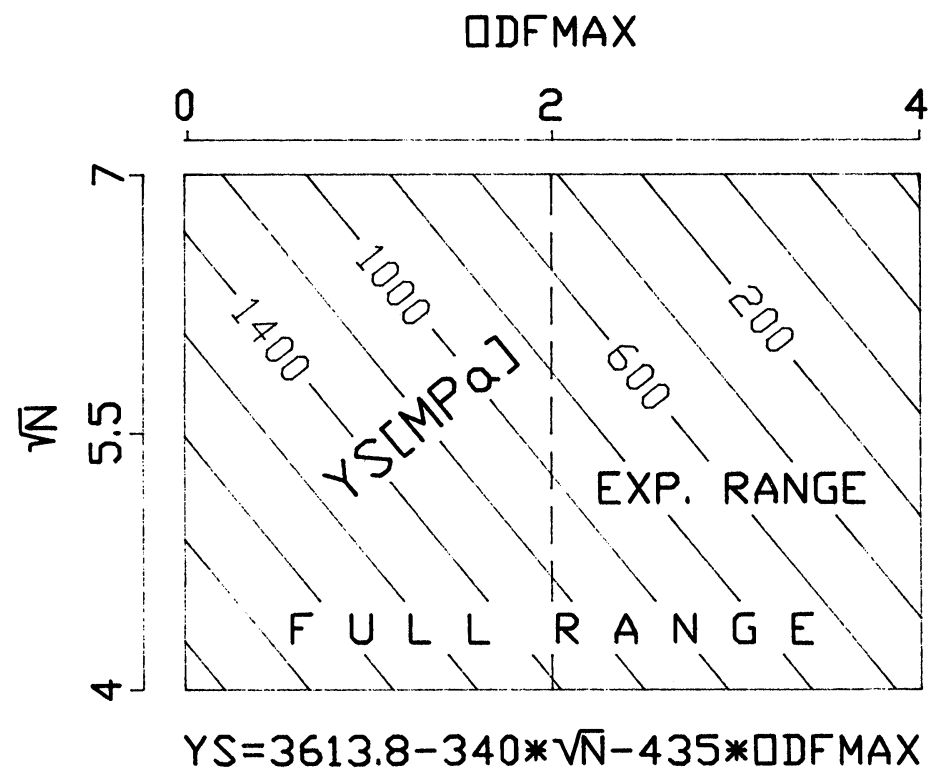

Figure 10 Results of regression analysis of annealed wires. Yield strength (YS) is shown as correlated to the free path between the spherulites $(\sqrt{ } N)$, and the texture parameter (ODFMAX). Isolines of YS [Mpa] are drawn.

ODFMAX is shown in Figure 8. Here again yield strength is shown in the form of isolines. Looking at Figure 8 it should be mentioned that here the aspect ratio parameter $(1 / \sqrt{ } A R)$, characterizing the microstructure exerts a much stronger influence than ODFMAX.

For the annealed wires similar regression analyses were made, again using ODFMAX, to characterize texture, while grain size $(1 \sqrt{ } D)$, mean distance of second phase spherulites $(\sqrt{ } N)$ were used to characterize microstructure. Yield strength (YS) was used in the regression analyses. Figure 9 gives the result of regression analysis for the annealed wires, correlating $1 \sqrt{ } D$ and ODFMAX to (YS). It is seen from Figure 9 that here ODFMAX exerts a stronger influence, while the effect of the grain size parameter $(1 \sqrt{ } D)$ cannot be excluded.

The results of another regression analysis that correlated YS to $V_{N}$ and ODFMAX is presented in Figure 10. Here again we can observe that microstructure $(\sqrt{ } N)$ and texture (ODFMAX) exert an almost comparable influence.

\section{DISCUSSION AND CONCLUSIONS}

The first observation we have to make about the nature of the textures observed in these wires is that they seem to be surprisingly similar to those observed in respective cold rolled and annealed steel sheet specimens [(Schlippenbach (1986), Misra (1984)]. If we remember that cold drawing is basically axially symmetrical deformation whereas rolling is assumed to be plane strain deformation, this is certainly not what we should expect. In fact, as these stress and strain states are 
only idealized forms, only true in the very central part of the deformed material, the similarity of the two kinds of textures should be taken as an indication of a similarity of the stress and strain paths in these materials.

An alternate explanation of such similarity is that the initial textures that are taken over from casting, swaging, and hot deformation have such an overbearing effect on texture development, that subsequent cold deformation cannot completely erase these effects.

The main issue, however, that we have to address here, is to find out how texture and microstructural parameters really affect mechanical properties. If we look at the results of our regression analysis for cold drawn wires it is fair to say that the aspect parameter ratio, $1 \sqrt{ } A R$, the maximum ODF, ODFMAX exert roughly the same order of influence on the homogeneous strain energy (EHOM) Figure (7), while in the case of yield strength (YS) the aspect ratio has shown to have a stronger influence (Figure 8).

We have only shown here those regression relationships that indicated a very good correlation (with $R^{2}$-values exceeding 0.85 ). Other, poorer relationships were also studied to investigate the full consequence of the choice and the number of correlating parameters.

The question of other texture parameters should also be dealt with. No doubt, from the scientific point of view, we should be prompted to think that parameters like Taylor-factor, or $R$-value should be more suited to characterize properties in regressions. Our findings, however, do not seem to back up this view. This may be due to the fact that neither the Taylor-factor, nor the $R$-value are primarily suited to appropriately characterize monoaxial strength properties (YS), (UCS), (EHOM). Texture sharpness, that is ODFMAX, may reflect several important characteristics.

Finally the question of weighing the influences of texture and microstructure should be answered as explicitly as our findings permit. Looking through all our results, we find that, in the case of cold drawn, and spheroidization treated low-C wires, texture exerts an influence comparable to that of microstructure in most cases. We have also however noted, that this is not always so, and in some cases microstructural parameters exert an overbearing influence.

In conclusion we state that, according to our investigation, both texture and microstructure exert significant influences on the mechanical properties.

The textures of all these wires, cold drawn, and annealed, are best described by the two fibres. The $\langle 110\rangle$ fibre parallel to the wire axis is a typical drawn, texture. The $\langle 111\rangle$ fibre normal to the wire axis, although strong in the cold drawn texture, becomes the major texture component after annealing. The single $\{111\}\langle 110\rangle$ orientation also provides a good approximation of these textures.

For the cold drawn wires the aspect ratio parameter $(1 / \sqrt{ } A R)$ and the texture parameter (ODFMAX) correlated well with the homogeneous strain energy (EHOM) and also with the yield strength (YS). In the case of (YS) the parameter $(1 / \sqrt{ } A R)$ has shown a stronger influence.

The mechanical properties of annealed wires correlated well to the grain size parameter $(1 \sqrt{ } D)$, to the mean spherulite particle distance $(\sqrt{ } N)$ and to ODFMAX. The weight of the influence of microstructural parameters $(1 \sqrt{ } D)$ and $(\sqrt{ } N)$ was the same as the texture parameter (ODFMAX) as correlated to yield strength (YS). 


\section{ACKNOWLEDGEMENTS}

Thanks are due to the World University Service of Canada for providing a fellowship for Mr. Sugondo enabling him to pursue his studies and research in Canada. One of the authors, Dr. P. Gangli, wishes to acknowledge the financial support of Natural Science and Research Council (NSERC) for partial funding of this project. Thanks are also due to STELCO Steel Company for providing our specimens.

\section{References}

Abbruzzese, G. (1989) 'Metallurgical conditions for development of adequate magnetic properties in grain oriented silicon iron', IEEE Transactions on Magnetics, 25, p. 5, 3955.

Abbruzzese, G. and Lücke, K. (1986) 'A theory of texture controlled grain growth', Acta Metallurgica, 34, p. 905-914.

Barrett, B. S. and Levenson, L. H. (1939) 'Structure of Iron After Drawing, Swaging and Elongation in Tension', Trans. AIME, 135, p. 327.

Bhandary, S. and Cullity, B. D. (1962) 'The Texture and Mechanical Properties of Iron Wires Recrystallized in Magnetic Field', Trans. AIME, 224, p. 1194.

Bunge, H. J. (1982) Texture Analysis In Materials Science, Butterworths, London.

Campagnac, M. H. and Vassel, A. (1986) 'Influence of microstructure on tensile and fracture toughness properties of Ti-10V-2Fe-3Al alloy', Designing with Titanium, The Institute of Metals, London, p. 261-266.

Cullity, B. D. and Freda, A. (1958) 'Quantitative Method for Determination of Fiber Texture', Journal of Applied Physics, 29, p. 25.

Dieter, G. E. (1976) Mechanical Metallurgy, McGraw-Hill.

Ettisch, M., Polanyi, M. and Weissenberg, K. (1921) 'Über Faserstruktur bei Metallen', Z. Phys. 7, p. 181.

Gubchevski, V. P., Zemlyanskov, V. A., Zlatoustovski, D. M., Zlatustovskaya, L. D. and Nemkina, E. D. (1975) 'Formation of Texture in Wire Drawing', Steel in USSR, 5, p. 277.

Jensen, D. J. and Hansen, N. (1985) 'Effect of thermal processing on the texture and microstructure of aluminium', Strength of Metals and Alloys (ICSMA 7) (ed.) McQueen, H. J., Vol. 1, p. 263-268, Pergamon Press, Oxford.

Kanetsuki, Y. and Ogawa, R. (1981) 'Influence of Wire, Rod Diameter on Mechanical Properties of High Carbon Steel Wire During Patenting', Technical Bulletin 116 Kobelco Steel, Japan.

Lee, D. N., Chung, Y. H. and Shin, M. C. (1984) 'Preferred orientation in extruded aluminum alloy rod', ICOTOM-7, p. 109.

Mecking, H. (1979) 'Deformation in Polycrystals', Proc. ICSMA 5, (ed.) Haasen, P. Gerold, V., and Kostorz, G., Pergammon, p. 1573-1594.

Misra, S., Därmann, C. and Lücke, K. (1984) 'On the development of the Goss texture in iron - 3\% silicon', Acta Metallurgica, 32, p. 2185.

Moulin, L., Reschke, S. and Tenckhoft, T. (1984) 'Correlation between fabrication parameters, microstructure, and texture in Zircalloy tubing' in. Zirconium in the nuclear industry (ed.) D. G. Franklin, ASTM, p. 225-240.

Rollett, A. D. and Kocks, F. (1988) 'Computer Simulation of Pencil Glide in BCC Metals' ICOTOM-8, The Metallurgical Society, p. 375.

Sachs, G. (1928) 'Zur Ableitung einer Fliessbedingung', Z. Ver. Deutsch, Ing, 72(22) p. 734.

Von Schlippenbach, U., Emren, F. F. and Lücke, K. (1986), 'Investigation of the development of the cold rolling texture development in deep drawing steels by ODF analysis', Acta Metallurgica, 34, No. 7, p. 1289.

Sellars, C. M. (1982) 'Static Recrystallization and Precipation During Hot Rolling of Microalloyed Steels', in Deformation Processing and Structure, (ed.) G. Krauss, ASM, p. 245.

Sugondo, Szpunar, J. and Gangli, P. (1990) 'Development of texture in low-C steels used for cold heading', to be published. 